\title{
TLR2 ligand-synthetic long peptide conjugates effectively stimulate tumor-draining lymph node $T$ cells of cervical cancer patients
}

\author{
Gijs G. Zom ${ }^{1}$, Marij J.P. Welters ${ }^{2}$, Nikki M. Loof ${ }^{2}$, Renske Goedemans ${ }^{2}$, Sinéad \\ Lougheed ${ }^{3}$, Rob R.P.M. Valentijn ${ }^{4}$, Maarten L. Zandvliet ${ }^{4}$, Nico J. Meeuwenoord ${ }^{5}$, \\ Cornelis J.M. Melief ${ }^{1,6}$, Tanja D. de Gruijli3, Gijsbert A. Van der Marel ${ }^{5}$, Dmitri \\ V. Filippov ${ }^{5}$, Ferry Ossendorp ${ }^{1, *}$, Sjoerd H. Van der Burg ${ }^{2, *}$ \\ ${ }^{1}$ Department of Immunohematology and Blood Transfusion, Section Tumorimmunology, Leiden University Medical Center, \\ Leiden, The Netherlands \\ ${ }^{2}$ Department of Clinical Oncology, Leiden University Medical Center, Leiden, The Netherlands \\ ${ }^{3}$ Department of Medical Oncology, VU University Medical Center, Amsterdam, The Netherlands \\ ${ }^{4}$ Department of Clinical Pharmacy and Toxicology, Leiden University Medical Center, Leiden, The Netherlands \\ ${ }^{5}$ Leiden Institute of Chemistry, University of Leiden, Leiden, The Netherlands \\ ${ }^{6}$ ISA Pharmaceuticals BV, Leiden, The Netherlands \\ *These authors have contributed equally to this work \\ Correspondence to: Ferry Ossendorp, email: f.a.ossendorp@lumc.nl \\ Sjoerd H. Van der Burg, email: shvdburg@lumc.nl \\ Keywords: Toll-like receptor ligand, conjugate, synthetic long peptide, cancer vaccine, cervical cancer \\ Received: April 19, $2016 \quad$ Accepted: July 10, $2016 \quad$ Published: August 23, 2016
}

\section{ABSTRACT}

The potency of human papillomavirus type 16 (HPV16)-encoded synthetic long peptides (SLP), conjugated to an optimized Toll-like receptor 2 ligand (TLR2-L), was assessed in ex vivo activation of $\mathrm{HPV} \mathrm{6}^{+}$cancer patient-derived T cells. Two highly immunogenic SLP sequences derived from the oncogenic E6 protein of HPV16 were selected and conjugated to a Pam3CSK4-based TLR2-L under GMP conditions. Both conjugates were able to mature human DCs in vitro and to activate human skinderived antigen-presenting cells (APCs) upon intradermal injection in an ex vivo skin model, associated with induction of a favorable chemokine profile to attract and activate $T$ cells. The conjugated SLPs were efficiently processed by APCs, since HPV16specific $\mathrm{CD}^{+}$and $\mathrm{CD8}^{+} \mathrm{T}$-cell clones isolated from HPV16+ cervical tumors proliferated in response to both conjugates. The TLR2-L SLP conjugates significantly enhanced ex vivo $\mathrm{T}$ helper type $1 \mathrm{~T}$-cell activation in cell suspensions obtained from tumor-draining lymph nodes (LN) resected during hysterectomy of $\mathrm{HPV}^{16}{ }^{+}$cervical cancer patients. These results show that TLR2-L SLP conjugates can activate circulating or LN-derived tumor-specific $\mathbf{T}$ cells, a promising outcome for studying these two conjugates in a phase I/II clinical safety and immunogenicity trial.

\section{INTRODUCTION}

Cancer immunotherapy aims to instruct the patient's immune system to eradicate tumors. Synthetic long peptide (SLP)-based vaccines constitute such a therapy to augment pre-existing, but often weak or suppressed, $\mathrm{T}$ cell responses in cancer patients. Synthetic long peptides (SLPs) are processing-dependent linear amino acid sequences harboring multiple potential $\mathrm{CD}^{+}$and $\mathrm{CD} 8^{+} \mathrm{T}$ cell epitopes that are expressed by tumor cells. We have previously reported the immunological advantages of these chemically well-defined long peptide vaccines, that are readily produced under GMP $[1,2]$.

In-depth analysis of $\mathrm{T}$ cell responses in the tumor and in tumor-draining lymph nodes (LN) of HPV $16^{+}$cervical cancer patients revealed that $\mathrm{T}$ cells directed against multiple epitopes of the HPV16 E6 and E7 oncoproteins are present, not as fully activated $\mathrm{T}$ cells, but poised for action [3]. Indeed, reactivation of these T cells can readily be achieved by vaccinating HPV $16^{+}$cervical cancer 
patients with an SLP vaccine consisting of overlapping SLPs covering HPV16 E6 and E7 [4, 5]. Clinical benefit of SLP vaccination was established in patients with HPV16induced premalignant lesions. At 12 months of follow-up, clinical responses were observed in 52 to $79 \%$ of patients with high-grade vulvar and vaginal intraepithelial neoplasia (VIN/VaIN), as recently reported in two independent clinical trials studying the efficacy of the HPV16 SLP vaccine $[6,7]$. Immune monitoring showed that SLP vaccination induced HPV16-specific T cell responses in all patients and that clinical efficacy correlated with a strong IFN $\gamma$-associated $\mathrm{T}$ cell response in both trials.

SLP vaccination induces strong $\mathrm{CD}^{+} \mathrm{T}$ cell responses. The $\mathrm{CD}^{+} \mathrm{T}$ cell responses are weaker and more difficult to detect, suggesting that these cells require efficient boosting, e.g. by the addition of an effective adjuvant [8, 9]. TLR-ligands are generally well-known for their capacity to boost $\mathrm{T}$ cell responses in vivo [10-12]. A study by De Vos van Steenwijk et al showed that ex vivo stimulation of cervical cancer-infiltrated and tumor draining-LN T cells using specific peptides mixed with a TLR agonist resulted in a strongly enhanced IFN $\gamma$ expression [3]. Although the application of imiquimod at the vaccination site in our recent HPV16 SLP clinical trial did not improve $\mathrm{T}$ cell responses and clinical outcome, the application of TLR-ligands in cancer vaccines remains promising when provided in an optimal setting [13].

Covalent conjugation of a TLR2-L to SLPs constitutes an even more sophisticated approach to improve the current HPV16 SLP vaccine [14-17]. In murine models, we have shown that TLR2-L SLP conjugates are targeted in vivo to antigen-presenting cells (APCs) expressing TLR2 and thereby improve antigen uptake, simultaneously maturing these APCs $[14,18]$. This dual effect on the APCs resulted in strongly increased $\mathrm{T}$ cell priming in vivo, as well as enhanced induction of anti-tumor immunity [15]. Importantly, the improved efficacy of TLR2-L SLP conjugates allows a significant reduction in dose, thereby potentially reducing the risk of injection site reactions $[6,7,19]$.

Upon injection, vaccine components readily gain access to several local APC types, which can subsequently ingest the antigen and become activated by adjuvantformulated vaccines. Intradermal injection of HPV16 SLPs without adjuvants was shown to induce circulating and skin-infiltrating HPV16-specific $\mathrm{CD}^{+}$and $\mathrm{CD}^{+} \mathrm{T}$ cells [20]. Adjuvants have the capacity to modulate local skin-associated APCs to induce either a Th1- or Th2-type response by upregulation of co-stimulatory activation markers and expression of cytokines and chemokines [21]. By conjugating a TLR2-L to an SLP, we have developed a synthetically well-defined vaccine that has the potency to cause local innate immune activation, antigen-targeting to DC and DC activation, together leading to efficient $\mathrm{T}$ cell activation.

The present study describes the development, immunological potency and capacity to prime and boost cancer patient-derived T cells ex vivo of TLR2-L SLP conjugates that are currently tested in a clinical trial. We show that the TLR2-L SLP conjugates induce significant activation of HPV16-specific $\mathrm{CD}^{+}$and $\mathrm{CD}^{+} \mathrm{T}$ cells and robust expression of IFN $\gamma$ and/or IL-2 by ex vivo stimulated tumor-draining LN-derived T cells of cervical cancer patients.

\section{RESULTS}

\section{Synthetic long peptide amino acid sequences 71-95 and 127-158 of the HPV16 E6 protein represent highly immunogenic regions}

The current HPV16 SLP vaccine consists of thirteen peptides covering the entire amino acid sequences of the HPV16 E6 and E7 oncogenic proteins. For proof of principle, we decided to select the two most immunogenic regions of the HPV16 E6 antigen, based on the spontaneous immune reactivity in healthy immune donors without evidence of virus infection. Two SLPs representing these two regions were used for conjugation to the optimized TLR2-ligand Amplivant ${ }^{\mathrm{TM}}$ (AV), followed by pre-clinical testing of their functionality. Based on the spontaneous immune reactivity in the protected healthy donors the C-terminal half of the HPV16 E6 protein constitutes the most immunogenic region (Supplementary Figure S1A) [22, 23]. In agreement with these results, tumor-draining LN cells derived from 9 cervical cancer patients (De Vos van Steenwijk et al [3] and unpublished data) predominantly responded to epitopes present in the center and C-terminal region of E6 (Supplementary Figure S1B). Subsequently, we analyzed three cervical cancer patients who responded to the C-terminal half of E6 after vaccination with the HPV16 SLP vaccine [4], to identify which peptides contained in the vaccine were the most immunogenic. All three tested PBMC samples showed a strong response against epitopes within the HPV16 E6 7195 and 127-158 SLPs (Figure 1A). Analysis of these two peptides using the MHC algorithm databases IEDB and SYFPEITHI revealed that both SLP sequences harbor a multitude of potential HLA class I- and II-binding epitopes for frequent HLA-alleles in The Netherlands (Table 1). Based on these combined findings, the HPV16 E6 71-95 $\left(\mathrm{SLP}_{71-95}\right)$ and 127-158 (SLP $\left.{ }_{127-158}\right)$ SLPs were selected for conjugation to a TLR2-L.

\section{HPV16 E6-derived SLPs conjugated to TLR2-L mature human dendritic cells and induce chemokine responses}

We generated conjugates of the two selected HPV16 E6-derived SLPs by in-line peptide synthesis and final attachment to AV as described by Khan et al (Figure 2 and Supplementary Figure S2) [14]. AV is an improved Pam3CSK4-based TLR2-binding ligand, generated by 
modifying one of the three lipid tails of Pam3CSK4 to enhance binding of AV to its receptor. AV was shown to induce stronger maturation of murine DCs than Pam3CSK4 [24]. AV and AV-SLP conjugates induced activation of TLR2-expressing HEK293 cells but not wildtype HEK293 cells (Supplementary Figure S3), showing that AV and the AV-SLP conjugates specifically activate cells through TLR2. To determine whether AV retains its potency to induce DC maturation and activation after conjugation to long peptides, monocyte-derived DCs (moDC) were incubated with each of the conjugates or AV alone. After co-culture for 24 hours, the concentration of IL-12p40 in the supernatant was measured by ELISA. Both AV-SLP conjugates and AV alone triggered IL$12 \mathrm{p} 40$ production (Figure $3 \mathrm{~A}$ ) and the expression of the maturation markers CD83, CD86 and HLA-DR (Figure $3 \mathrm{~B})$. Despite reports on the occurrence of polymorphisms in the TLR2 gene locus [25-27], we have reproducibly observed maturation of human moDCs derived from PBMC of all tested healthy donors ( $n=20$, data not shown). This shows that AV can target and activate relevant APCs irrespective of potential TLR polymorphisms in the patient population. AV and AV-SLP conjugates also triggered the production of chemokines by DCs. Incubation of human moDCs with AV or with the conjugates induced the secretion of IL-8, IL-10, MCP-1, CCL3, CCL4 and CCL5 (Figure 3C), albeit not to the same levels as seen after incubation of DCs with the strong TLR4 agonist LPS.

\section{Induction of a favorable, $T$ cell attracting, chemokine profile by TLR2-L SLP conjugates in human skin explants}

Intradermal vaccination of AV-SLPs offers an attractive alternative for SLP vaccination $[20,28]$ to avoid side effects by Montanide emulsions $[6,7,19]$. We studied the potency of the AV-SLP conjugates in activating skin- associated cells upon intradermal injection by making use of skin explants from four different healthy donors (Figure 4) [29]. Directly following intradermal injection, a $6 \mathrm{~mm}$ diameter biopsy was taken from the area of the injection site. Skin-migratory cells were allowed to migrate for 48 hours from the biopsy into culture medium-filled wells. Flow cytometry analysis revealed that on average approximately $75 \%$ of migrated cells were CD $11 \mathrm{c}^{+}$ (ranging from $50 \%$ to $90 \%$ ). The composition of CD1a ${ }^{+}$ and $\mathrm{CD}_{14}{ }^{+}$migratory DC subsets was not significantly changed after injection of the AV-SLPs (Supplementary Figure S4B). Chemokine levels in the skin supernatants were measured using ELISA (IL-8) or Luminex. The concentrations of IL-1 $\beta$, CCL4, IL-10 and in particular IL-8 and CCL3 were increased in all biopsies injected with AV-SLPs compared to SLP-injected skin biopsies. This confirms our in vitro data on $\mathrm{AV}$-stimulation of moDC and demonstrates that intradermal injection of the AVSLPs or mixtures of AV and SLP stimulates stronger local inflammation than injection of free SLPs. It also shows that $\mathrm{AV}$ retains its adjuvant potency upon conjugation to SLPs after injection in human skin.

\section{AV-SLPs induce T cell proliferation of HPV16- specific CD8 and CD4 $\mathrm{T}$ cell clones}

Next, we determined whether the conjugated peptides are processed by APCs and whether the embedded MHC class I and II epitopes are properly presented. Three T cell clones responding to the selected peptides were isolated from cervical cancer infiltrating lymphocytes of two patients [30]. From these clones, $\mathrm{CD}^{+} \mathrm{T}$ cell clone C331.2 and $\mathrm{CD}^{+} \mathrm{T}$ cell clone $\mathrm{C} 331.11$ are specific for an epitope in $\mathrm{SLP}_{127-158}$, while $\mathrm{CD}^{+} \mathrm{T}$ cell clone $\mathrm{C} 427.215$ is specific for an epitope in $\mathrm{SLP}_{71-95}$. HLA-matched moDCs were pulsed for 24 hours with the AV-SLP conjugates, free AV or SLP alone and subsequently used to stimulate the T cell clones.
Patient C301

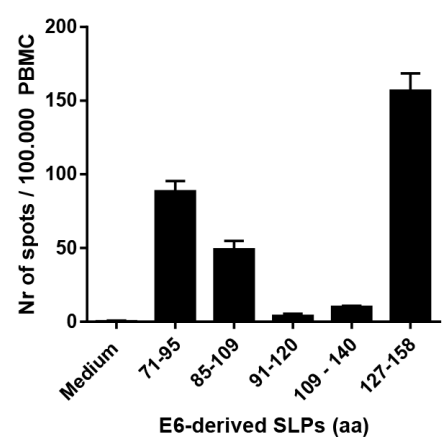

Patient C369

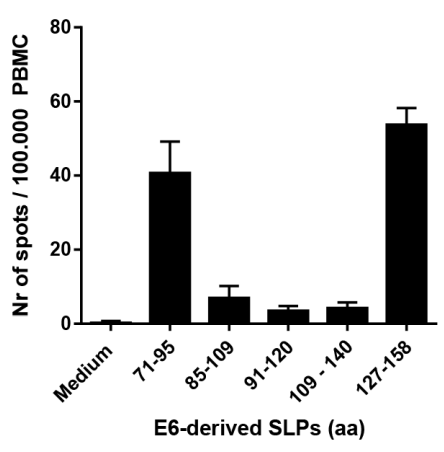

Patient C388

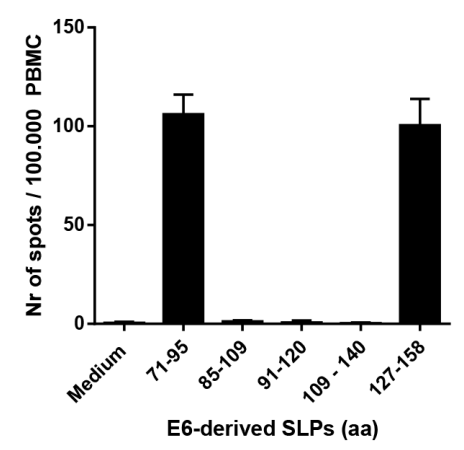

Figure 1: Synthetic long peptides (SLPs) with amino acid (aa) sequences E6 71-95 $_{\text {and E6 }}$ induce strong IFN $\gamma$ responses in PBMC of cervical cancer patients. PBMC of three cervical cancer patients (C301, C369 and C388) were tested. Data represent average spot counts of quadruplicate wells with standard deviations in the IFN $\gamma$ ELISpot assay after peptide stimulation of PBMC for 4 days. Horizontal axis: amino acid sequences of HPV16 E6-derived peptides used to stimulate PBMC. 
Table 1: Number of predicted HLA-binding peptides within the indicated amino acid sequences of HPV16 E6, using two online epitope prediction algorithms

\begin{tabular}{lcc}
\hline & E6 71-95 & E6 127-158 \\
\hline HLA-A*01:01 & 4 & 1 \\
HLA-A*02:01 & 3 & 2 \\
HLA-A*03:01 & 3 & 4 \\
HLA-A*11:01 & 3 & 4 \\
HLA-A*24:02 & 8 & 2 \\
HLA-A*26:01 & 4 & 0 \\
HLA-B*07:02 & 3 & 2 \\
HLA-B*08:01 & 2 & 4 \\
HLA-B*15:01 & 2 & 0 \\
HLA-B*35:01 & 4 & 0 \\
HLA-B*40:01 & 2 & 1 \\
HLA-B*44:02 & 3 & 1 \\
HLA-B*51:01 & 2 & 1 \\
HLA-DR1*B01 & 2 & 3 \\
HLA-DR1*B03 & 2 & 1 \\
HLA-DR1*B04 & 1 & 2 \\
HLA-DR1*B07 & 2 & 3 \\
HLA-DR1*B11 & 1 & 1 \\
HLA-DR1*B15 & 3 & 3 \\
\hline
\end{tabular}

The activation of $\mathrm{CD} 8^{+} \mathrm{T}$ cell clone $\mathrm{C} 331.2$, measured by proliferation and IFN $\gamma$ production, was much stronger to DCs loaded with AV-SLP ${ }_{127-158}$ than with SLP only (Figure $5 \mathrm{~A})$. Both $\mathrm{CD}^{+} \mathrm{T}$ cell clones responded equally well to conjugated and non-conjugated SLP (Figure 5B, 5C). The non-specific proliferation of clone $\mathrm{C} 331.11$ when co-cultured with DCs stimulated with the highest dose of AV probably is due to the high maturation status of the stimulated DCs. Overall, these data show that the E6 SLPs conjugated to AV are taken up and processed efficiently by DCs to generate and present $\mathrm{T}$ cell epitopes in both MHC class I and II molecules. Remarkably, the activation of the $\mathrm{CD} 8^{+} \mathrm{T}$ cell clone was improved upon conjugation of the SLP to AV suggesting a more efficient processing and presentation of AV-SLP conjugates than the free SLPs into MHC class I.

\section{Cancer patient-derived lymph node $T$ cells produce more Th1-type cytokines upon stimulation with AV-SLP conjugates}

We have previously observed that tumor-draining $\mathrm{LN}$-derived $\mathrm{T}$ cells of a cervical cancer patient were able to respond against epitopes in both selected E6 SLPs [3]. Here we analyzed the ex vivo activation of these tumor-draining
LN cells after stimulation with the AV-SLP conjugates. Autologous monocytes were loaded with the individual AVSLP conjugates (AV-SLP ${ }_{71-95}$ or AV-SLP ${ }_{127-158}$ ), a mixture of free SLPs and AV or with free SLP for 24 hours and then used as APCs. A higher number of activated $\mathrm{CD} 4^{+} \mathrm{T}$ cells expressing CD154 (CD40L) was observed in the LN culture stimulated with AV-SLP as compared to the controls (Figure $6 \mathrm{~A}$ and $6 \mathrm{~B}$ ). Also the numbers of activated IFN $\gamma$ and IL-2 single and double producing T cells were higher when SLPs were conjugated to AV (Figure 6A and 6B). In addition, $\mathrm{CD} 8^{+} \mathrm{T}$ cell reactivity was improved as the number of IFN $\gamma$ producing $\mathrm{E}_{127-158}$-specific $\mathrm{CD} 8^{+} \mathrm{T}$ cells was also higher after stimulation with the AV-SLP conjugate (Figure 6C). These data show that $\mathrm{T}$ cells present in the tumor-draining $\mathrm{LN}$ can be more efficiently activated by stimulation with AVSLP conjugates than with the free SLPs or mixtures of free SLPs and AV.

\section{$T$ cell responses frequently observed in cervical cancer patient lymph node $T$ cell cultures upon in vitro stimulation}

Because we had identified SLPs that were recognized by a high proportion of cervical cancer patients 


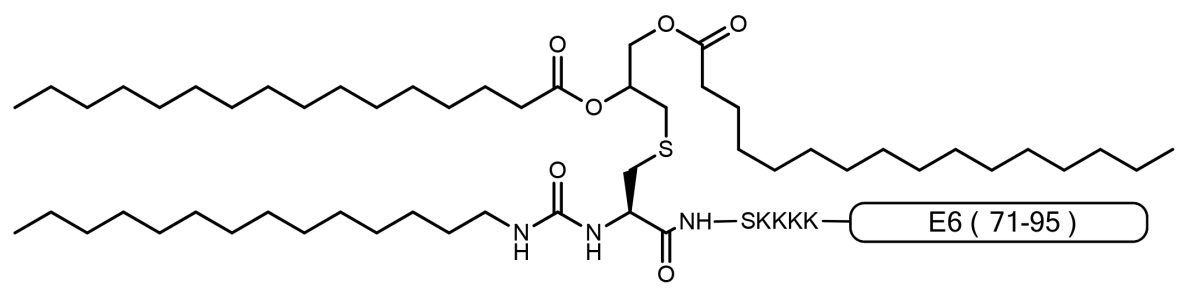

Amplivant-SLP E671-95

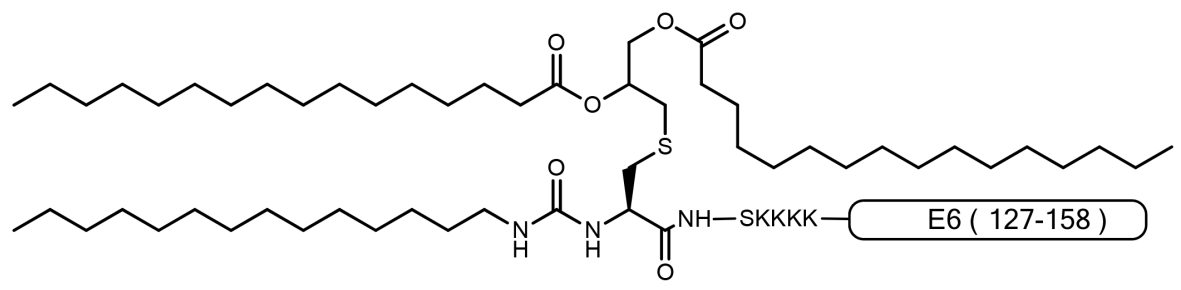

Amplivant-SLP E6127-158

Figure 2: Representation of AV-SLP conjugates with HPV16 E6-derived amino acid sequences 71-95 and 127-158.

A

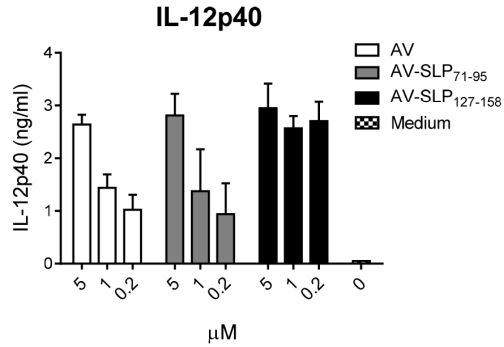

B

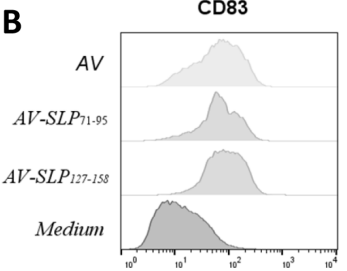

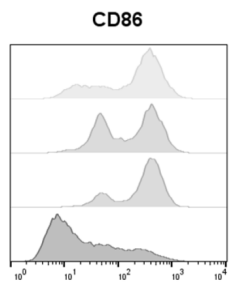

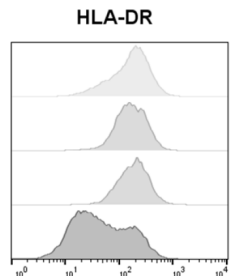

C

IL-8

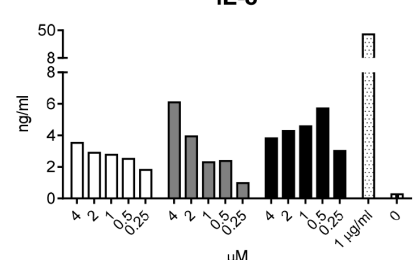

CCL3
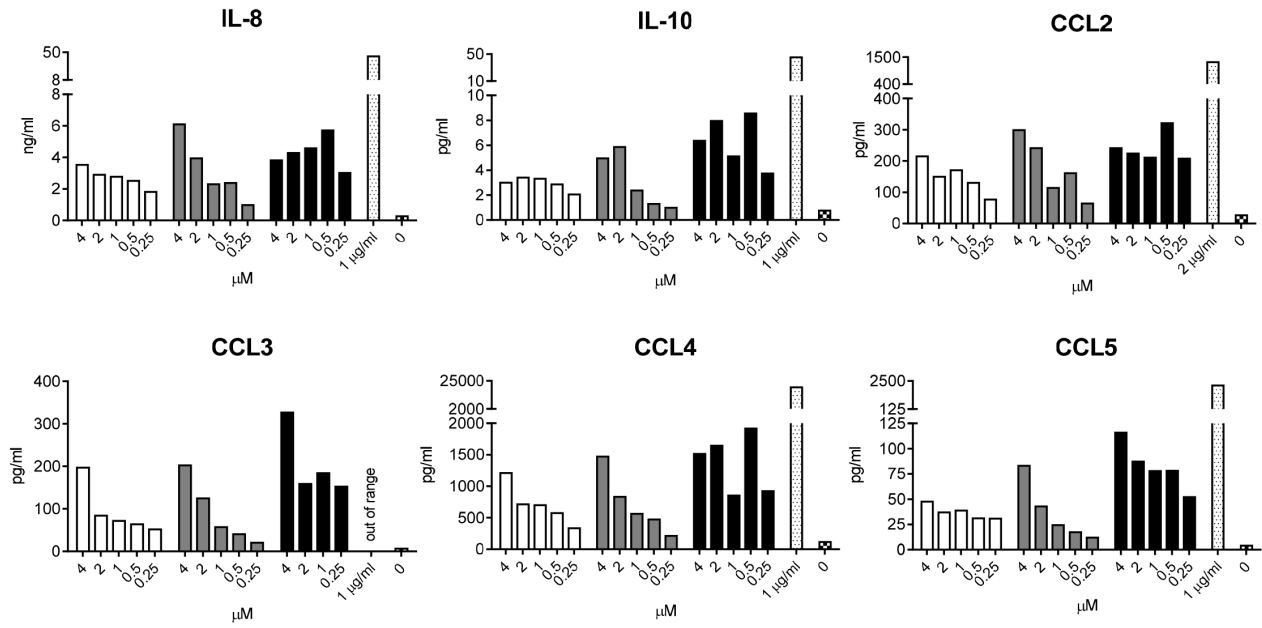

CCL4
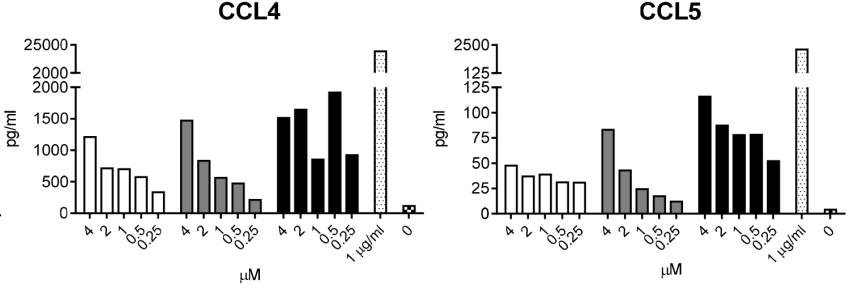

Figure 3: Conjugates of TLR2-L and HPV16-derived SLPs mature human DCs. A. Production of IL-12p40 as measured in supernatant of human monocyte-derived DCs (moDCs) from 1 donor stimulated with AV only (AV) or AV-SLP conjugates. Error bars represent standard deviation of triplicate wells. Data are representative for 5 similar experiments. B. Expression of co-stimulatory molecules CD83 and CD86 and HLA-DR on human moDCs after stimulation with $2 \mu \mathrm{M}$ of compounds as in (A). C. Concentrations of IL8, IL-10, MCP-1, CCL3, CCL4 and CCL5 in supernatant of human moDC stimulated with titrating doses of compounds, as measured by Luminex assay. TLR4-ligand LPS was added as a positive control. Data shown are representative of 5 similar experiments. 
and healthy individuals, we here tested the capacity of the AV-SLP conjugates to stimulate tumor-draining LN cells from randomly selected HPV $16^{+}$cervical cancer patients. LN mononuclear cells from six randomly chosen HPV16 ${ }^{+}$ cervical cancer patients were stimulated ex vivo with a mix of both AV-SLP conjugates, a mix of both free SLPs or medium as a control. Activation of HPV16 E6-specific T cells was measured by cytometric bead array (CBA) on supernatant collected after 7 or 8 days of culture. The detected concentrations of IFN $\gamma$, IL-5 and IL-10 were generally above the lower detection limits of the assay and ranged from $12.9 \mathrm{pg} / \mathrm{ml}-17.7 \mathrm{ng} / \mathrm{ml}$ (IFN $\gamma$ ), 2.5 - $325.2 \mathrm{pg} / \mathrm{ml}$ (IL-5), 4.5 - 172.4 pg/ml (IL-10). TNF $\alpha$ was not detected in the cultures of $\mathrm{C} 822$ and $\mathrm{C} 830$, and ranged from $7.4-77.5 \mathrm{pg} / \mathrm{ml}$ in the other cultures. The LN cultures of two out of six cancer patients showed an IFN $\gamma$ response after stimulation with the AV-SLP conjugates (C879, C896; Table 2). Both of the responding patients also showed induction of IL-5 upon stimulation with the AV-SLP conjugates. The LN culture derived from patient C822 responded to stimulation with free SLPs by producing IL-5 only. IL-10 and the Th2-associated cytokine IL-4 were also measured, but no significant levels could be detected in any of the supernatants. In addition, despite the lack of detectable cytokines in CBA, we could observe an increase in IFN $\gamma$-production in LN cell cultures obtained from patient C972 by ICS after 12 days of culture (Supplementary Figure S5). A suboptimal timing of measurement resulting in still high background activation levels of cells following the initial stimulation precluded the detection of responses using ICS in the other patient lymph node cell cultures. Overall, these findings show that in 3 (C879, C896 and C972) out of 6 tested HPV $16^{+}$cancer patients, LN T cells effectively responded to the two combined AV-SLP conjugates.

\section{DISCUSSION}

This study shows that the conjugation of SLPs to an optimized TLR2-L results in an enhanced potency to specifically activate cancer patient-derived $\mathrm{T}$ cells. We selected the two most immunogenic SLPs from the thirteen SLPs of a potential therapeutic HPV16 clinical vaccine for conjugation to a defined TLR2-L, designated Amplivant ${ }^{\mathrm{TM}}(\mathrm{AV})$. We showed that these AV-conjugated SLPs induce the activation and maturation of human DCs
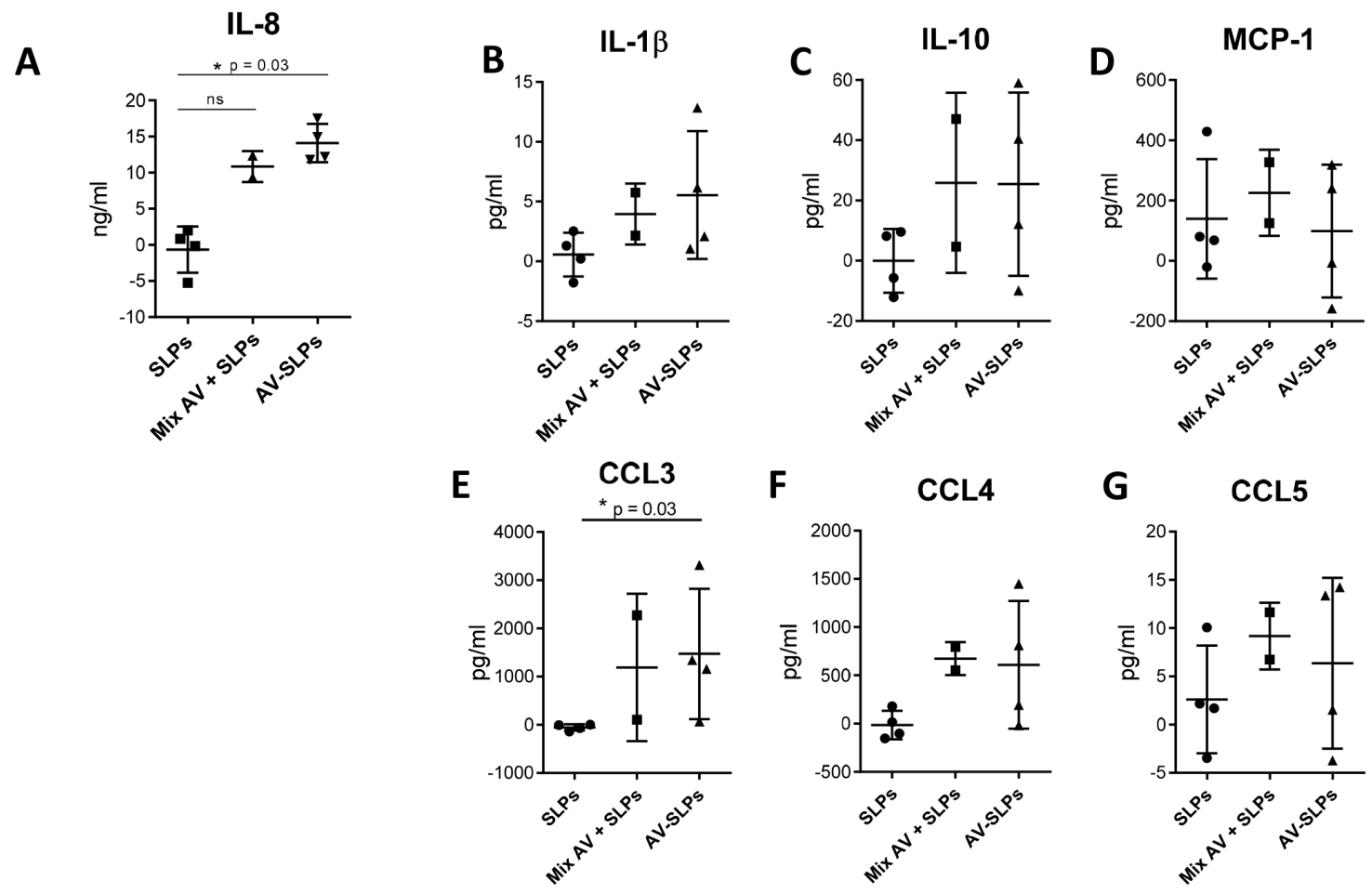

Figure 4: Conditioning of the skin microenvironment by AV-SLP conjugates at the vaccination site leads to the release of pro-inflammatory cytokines and chemokines. Cytokine and chemokine production by human skin-migratory cells after intradermal injection of a mix of HPV16 E6-derived $\mathrm{SLP}_{71-95}$ and $\mathrm{SLP}_{127-158}$, a mixture of AV with both SLPs or a mix of both AV-SLP conjugates in human skin explants $(\mathrm{n}=4)$. A. IL-8 concentration in supernatant, as measured by ELISA. B-G. IL-1 $\beta$, IL-10, MCP-1, CCL3, CCL4 and CCL5 concentration in supernatant as measured by Luminex assay. Background cytokine concentration in saline condition was subtracted from the test conditions of each donor skin. Error bars represent standard deviations of the 4 tested skin explants. Significant differences (* $\mathrm{p}<0.05$ ) determined by Mann Whitney U test. 
as well as promote local inflammation when injected into the human skin. The conjugates were processed efficiently, leading to a markedly improved activation of cloned tumor-infiltrating $\mathrm{CD}^{+} \mathrm{T}$ cells. In addition, the AVSLP conjugates effectively stimulated Th1-type cytokine $\mathrm{CD}^{+}$and/or $\mathrm{CD}^{+} \mathrm{T}$ cell-responses in tumor-draining LNderived T cells. Moreover, the AV-SLP conjugates could induce a specific IFN $\gamma^{+}$response in three out of six LN cell cultures derived from randomly selected HPV $16^{+}$cancer patients whereas free SLPs were able to do so in one out of six cultures.

The two HPV16 E6-derived SLPs were selected by analyzing T cell responses against HPV16 E6 and E7 as measured in healthy donors and lymph node material of cervical cancer patients. More $\mathrm{T}$ cell responses in cervical cancer patients are directed against the E6 than the $\mathrm{E} 7$ protein, as described in Kenter et al and Welters et al $[6,8]$. By analyzing $\mathrm{T}$ cell responses in previous studies, it was estimated that at least half of all HPV16positive individuals could mount a response against these two peptides. In addition to immunogenicity, logistic factors such as feasibility of chemical synthesis, solubility and formulation made us decide to select these two SLPs for conjugation. In this study we did not experience any relevant difficulties in synthesis and solubility of these two conjugates, not even when produced at a larger scale under GMP conditions (unpublished observations).

By choosing a TLR2-L for conjugation, we do not only aim to target the SLPs in vivo specifically to APCs that express TLR2 extracellularly, but also choose for a well-defined ligand that can be generated synthetically and may be modified for optimal efficacy. Moreover, it was previously shown that the TLR2-L Pam3CSK4 improved the IFN $\gamma$ response of tumor-infiltrating lymphocytes (TILs) after specific stimulation and had a slight advantage over Poly(I:C) and LPS in these assays [3]. We further aimed to optimize triggering of TLR2 by modifying Pam3CSK4, and generated AV in this manner [24].

Conjugation of AV to SLP sequences is not detrimental for its biological activity as shown by these two conjugates as well as with several other peptide sequences (our unpublished data). We observed a relative higher potency in DC maturation and TLR2-transfected HEK293 cell activation by the AV-SLP ${ }_{127-158}$ than the AV-SLP ${ }_{71-95}$ conjugate. Apparently, the physical and chemical properties of individual peptides can influence the biological activity of AV.
Clone number $\quad$ CD4 / CD8

C331.2

CD8

C427.215

CD4

C331.11

CD4
Proliferation

A

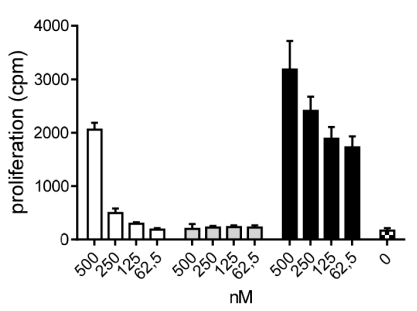

B

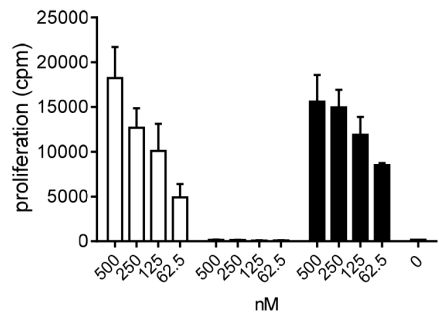

C

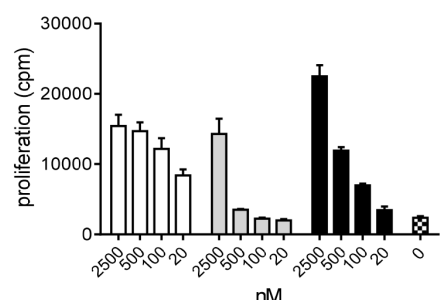

IFNy production
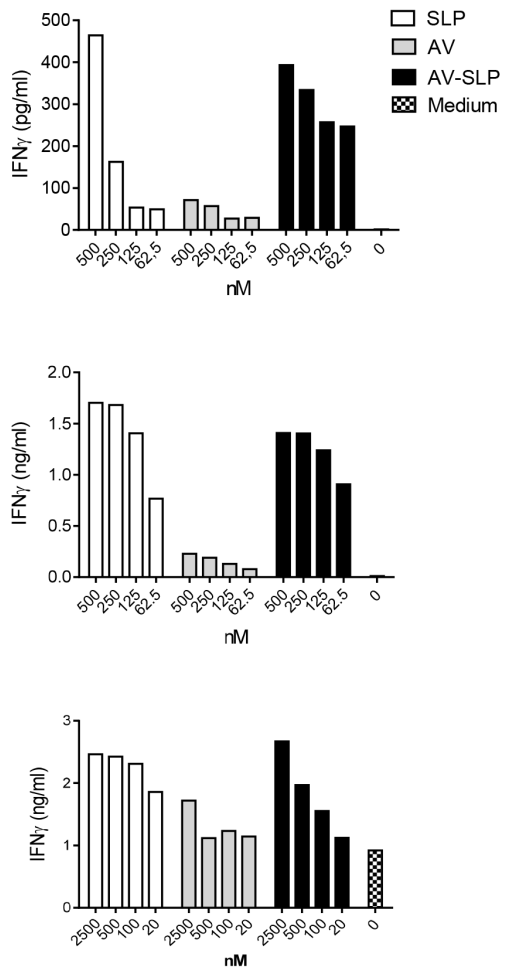

Figure 5: Enhanced $\mathrm{CD8}^{+}$and similar $\mathrm{CD4}^{+} \mathrm{T}$ cell clone proliferation induced by AV-SLP conjugates as compared to free SLP. Proliferation and IFN $\gamma$ production of A. $\mathrm{CD}^{+} \mathrm{T}$ cell clone $\mathrm{C} 331.2$ and $\mathbf{B}$. $\mathrm{CD}^{+} \mathrm{T}$ cell clone $\mathrm{C} 427.215$ after co-culture with HLA-matched moDCs loaded with SLP ${ }_{127-158^{\circ}}$ C. Proliferation and IFN $\gamma$ production of $\mathrm{CD}^{+} \mathrm{T}$ cell clone $\mathrm{C} 331.11$ after co-culture with HLA-matched moDCs loaded with $\mathrm{SLP}_{71-95}$. Error bars represent standard deviation of triplicate wells. 
Upon intradermal vaccination, local skinassociated APCs play an important role in the onset of the $\mathrm{T}$ cell response. To assess the effects of AV-SLP conjugates on these APCs, we made use of ex vivo human skin explant experiments in which we observed significantly enhanced concentrations of IL-8 and CCL3 upon stimulation with the AV-SLP conjugates. A similar trend was clearly observed for IL-1 $\beta$, IL-10 and CCL4. Of note, these current observations are in line with our previous observation that active TLR2 agonists impacted cytokine release rather than DC phenotype in this model system [21]. Importantly, the chemokine CCL3 can be highly relevant in a vaccination setting as it can recruit CCR1-, CCR3- and CCR5-expressing leukocytes, such as monocytes, NK cells, T cells and DCs. In addition, CCL3 has been associated with Th1-skewing in mice $[33,34]$.
Our recent in vivo analysis in tumor-bearing mice suggests that TLR2-L SLP conjugate vaccination positively impacts the Th1/Th2 balance as we see a strong CTL induction and efficient antitumor immunity [15]. The relevance of IL-10 production, as induced by AV in both DCs and skinmigrated cells, is ambiguous as this cytokine has been described both as a pro- and anti-inflammatory cytokine $[35,36]$.

The efficiency of peptide processing and presentation and subsequent $\mathrm{T}$ cell activation was studied using HPV16-specific $\mathrm{T}$ cell clones that recognize epitopes within the conjugated SLPs. These in vitro antigen presentation experiments showed that $\mathrm{CD}^{+} \mathrm{T}$ cells were activated significantly better by conjugates than by equimolar amounts of SLP or AV. Also CD4 ${ }^{+} \mathrm{T}$ cells were activated by conjugates in vitro although $\mathrm{CD}^{+} \mathrm{T}$

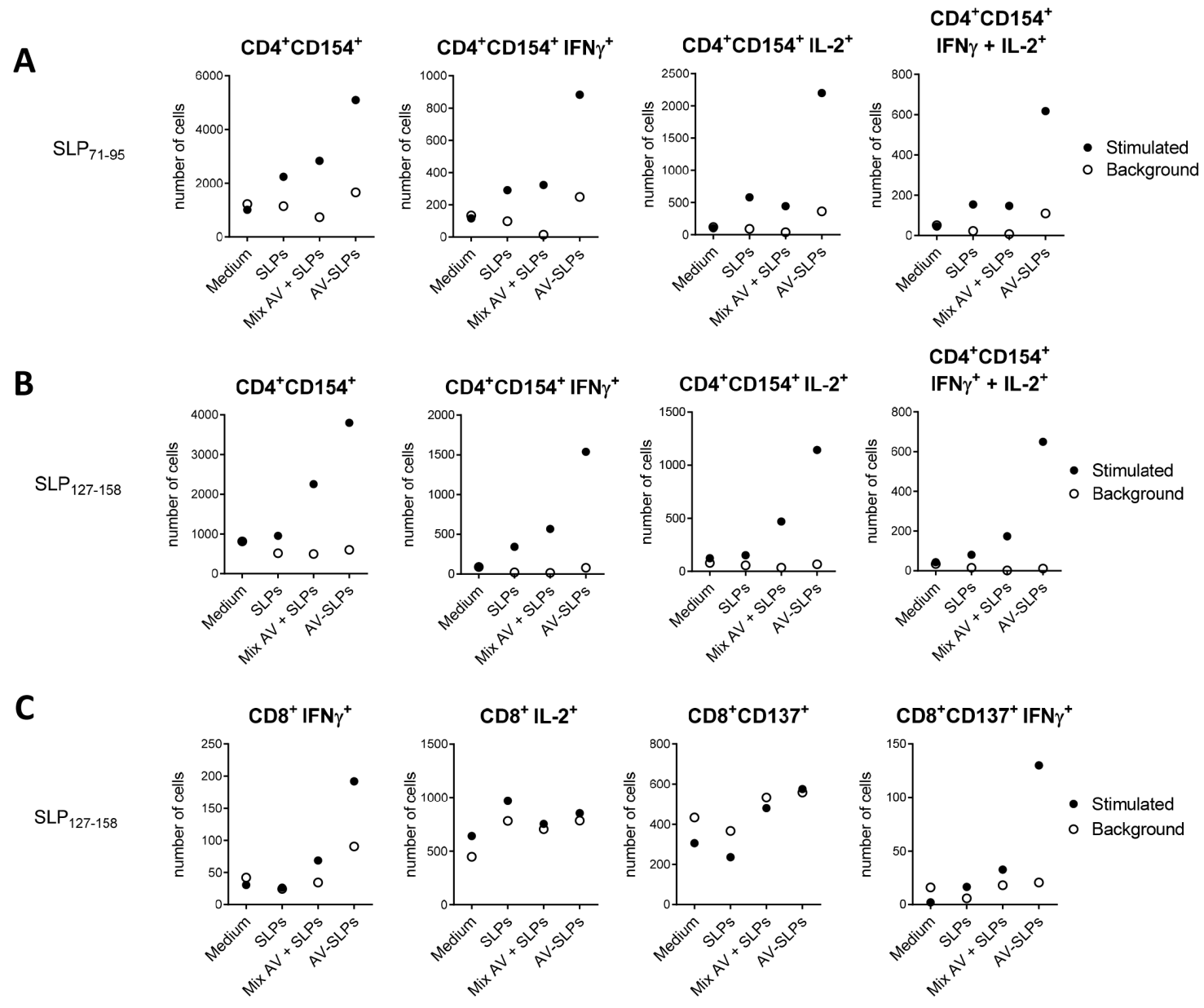

Figure 6: AV-SLP conjugates enhance IL-2 production by $\mathrm{CD}^{+} \mathrm{LN}$ T cells and IFN $\gamma$ production by $\mathrm{CD8}^{+} \mathrm{LN}_{\mathrm{T}}$ cells isolated from patient C427. A. Total number of cells in culture expressing CD $154^{+}$on $\mathrm{CD} 4^{+} \mathrm{T}$ cells specific for an epitope within $\mathrm{SLP}_{71-95}$, and total number of cells in culture expressing intracellular levels of IFN $\gamma$ and IL-2 in the indicated populations. Flow cytometry was performed after a 3-week co-culture of monocytes loaded with indicated compounds and LN-derived T cells. Background represents marker expression after re-stimulation of T cells one day prior to intracellular cytokine staining. SLPs: equimolar mix of HPV16 SLP ${ }_{71-95}$ and SLP ${ }_{127-158}$; AV-SLPs: equimolar mix of AV-SLP ${ }_{71-95}$ and AV-SLP ${ }_{127-158}$ B. Idem for CD4 ${ }^{+} \mathrm{T}$ cells specific for an epitope within E6 ${ }_{127-158^{\circ}}$ C. Idem for $\mathrm{CD}^{+} \mathrm{T}$ cells specific for an epitope within $\mathrm{E} 6_{127-158}$. 
Table 2: Cytokine responses measured in the supernatant of cervical cancer patient lymph node cell cultures

\begin{tabular}{|c|c|c|c|c|c|c|c|}
\hline & & C822 & $\mathrm{C} 830$ & C879 & C894 & C896 & C972 \\
\hline \multicolumn{8}{|l|}{$S L P S$} \\
\hline & $\mathrm{IFN} \gamma$ & $<1$ & $<1$ & 1.04 & $<1$ & 1.05 & 1.35 \\
\hline & $\mathrm{TNF} \alpha$ & $<1$ & $<1$ & 1.14 & $<1$ & $<1$ & 1.02 \\
\hline & IL-5 & 4.11 & $<1$ & 1.51 & $<1$ & $<1$ & $<1$ \\
\hline & IL-10 & $<1$ & 1.59 & $<1$ & $<1$ & $<1$ & 1.14 \\
\hline \multicolumn{8}{|l|}{$A V-S L P S$} \\
\hline & $\mathrm{IFN} \gamma$ & $<1$ & $<1$ & 5.98 & $<1$ & 5.71 & $<1$ \\
\hline & $\mathrm{TNF} \alpha$ & $<1$ & $<1$ & 1.81 & $<1$ & 2.75 & $<1$ \\
\hline & IL-5 & $<1$ & 1.49 & 12.09 & 1.55 & 5.49 & $<1$ \\
\hline & IL-10 & $<1$ & 1.55 & $<1$ & $<1$ & 2.89 & $<1$ \\
\hline
\end{tabular}

cell stimulation efficacy was similar by the corresponding free peptides. The latter finding has also been observed using mouse $\mathrm{CD}^{+} \mathrm{T}$ cells in vitro in our previous study [15]. This is most likely explained by differences in MHC class I and class II antigen processing pathways in DCs. However, our in vivo vaccination studies clearly show strong dependence on TLR2-L conjugation also for $\mathrm{CD}^{+} \mathrm{T}$ cell response induction [15], suggesting that the SLP-targeting effect of the TLR2-L to DCs is highly important for both $\mathrm{CD}^{+}$and $\mathrm{CD}^{+} \mathrm{T}$ cell activation in vivo. Therefore, covalent TLR2-L conjugation of T helper epitope-containing SLP is preferred above mixtures of these molecules since in vivo targeting and concomitant DC maturation are key in effective $\mathrm{T}$ cell priming and activation [18], not only by the induced expression of costimulatory molecules and relevant cytokines but also by storage of the targeted antigen in specialized compartments of dendritic cells to sustain antigen presentation in vivo [37]. Importantly, the targeting properties of AV-SLP conjugates allow a major dose reduction as compared to free SLPs. The current study presents in vitro data in which the targeting effect does not play a role. Therefore, the differences between free SLP and AV-conjugated SLP could rather be explained by enhanced uptake of the SLP, the co-stimulation provided to $\mathrm{T}$ cells by the matured APCs and the sustained peptide presentation.

Our data suggest that AV-SLP conjugates are more efficient at inducing a $\mathrm{T}$ cell response in the $\mathrm{LN}$ than free SLP. The availability of tumor-draining LN cells allowed us to analyze relevant $\mathrm{T}$ cell populations that were in close proximity to the tumor. We observed a clear increase of Th1-type cytokine production in these LN-derived specific $\mathrm{CD}^{+}$and $\mathrm{CD}^{+} \mathrm{T}$ cells. This indicates that $\mathrm{T}$ cells present in a potentially immunosuppressed tumor-draining area are likely to be poised for action in cancer patients [3], as they are still able to become activated and express a potentially beneficial Th1-phenotype. Also the observation that 3 out of $6 \mathrm{LN}$ cultures with unknown reactivity responded by IFN $\gamma$ production to AV-SLP conjugates and only 1 out of 6 cultures to free SLP suggests that otherwise undetectable HPV16-specific T cells can be efficiently stimulated by AV-conjugated SLPs. AV-SLP conjugates also appear to be able to induce Th2-type cytokines. The production of IL-5 coinciding with IFN $\gamma$ has also been observed before both in healthy donors, who have successfully cleared the virus [22] and upon SLP vaccination in previous clinical studies, which was associated with clinical responses $[3,4$, $19,38]$. It is therefore unlikely that this negatively impacts the induction of effective antitumor immunity.

The safety and immunological properties of the AVSLP conjugates are currently being examined in a phase I/II clinical trial in HPV16 ${ }^{+}$cancer patients (EudraCT: 2014-000658-12). Overall, this study provides evidence for the superiority of AV-SLP conjugates over free SLP as a vaccination modality to induce cancer patient-derived $\mathrm{T}$ cell responses.

\section{MATERIALS AND METHODS}

\section{Synthesis of AV-SLP conjugates}

Amplivant $^{\mathrm{TM}}$ (AV) was generated as described before [24], and conjugated to the N-terminus of HPV16 E6-derived SLPs amino acids 71-95 and 127-158 according to protocols described in Khan et al [14]. UVspectrum analysis of the generated conjugates shows a high purity of the syntheses $\left(98.7 \%\right.$ for AV-SLP ${ }_{71-95}$ and $99.3 \%$ for $\left.\mathrm{AV}-\mathrm{SLP}_{127-158} ; \mathrm{S} 2\right)$.

\section{Patient material}

Patient material was derived from women presenting with histologically proven cervical neoplasia at the department of Gynaecology of the Leiden University 
Medical Center and Haga Teaching Hospital, The Hague. These patients were enrolled in the CIRCLE study, which investigates cellular immunity against HPV16-positive cervical lesions after providing informed consent.

\section{MHC class I and II epitope prediction}

Epitope predictions in Table 1 are based on predictions from two online MHC class I and II binding algorithms (IEDB: http://www.iedb.org/ and SYFPEITHI: http://www.syfpeithi.de/). For IEDB, a peptide with a predicted $\mathrm{EC}_{50}$ below $8 \mathrm{nM}$ was considered a strong $\mathrm{MHC}$ binder. For SYFPEITHI, peptides scoring 15 or higher were considered strong MHC binders.

\section{ELISpot}

IFN $\gamma$ ELISpot was performed as described previously $[4,5,31]$. In short, PBMC samples of three cervical cancer patients were stimulated at a density of 2 $\mathrm{x} 10^{6} \mathrm{cell} \mathrm{s} / \mathrm{ml}$ for 4 days in IMDM medium supplemented with $10 \%$ human $\mathrm{AB}$ serum (Life Technologies) in the presence of $5 \mu \mathrm{g} / \mathrm{ml}$ of indicated peptides. Next, the stimulated PBMC were transferred to an anti-IFN $\gamma$-coated (Mabtech) Multiscreen 96-wells plate (Millipore), seeded in quadruplicates at a density of $5 \times 10^{5} /$ well. After 24 hours of incubation, the Multiscreen plate was developed according to the manufacturer's instructions (Mabtech). IFN $\gamma$-positive spots were counted on a BioSys 5000 video-imaging system. Specific spots were calculated by subtracting the mean value $+2 \mathrm{xSD}$ of the medium control wells from the experimental wells. Samples were considered positive when at least 10 spots were measured and the number of spots exceeded the mean number of spots of medium wells by at least 2 -fold.

\section{Monocyte-derived dendritic cell maturation and HEK293 cell activation}

Peripheral blood mononuclear cells (PBMC) from healthy donors (Sanquin) were isolated by centrifugation over a Ficoll gradient. Using magnetic CD14 Microbeads (Miltenyi), the $\mathrm{CD}_{1} 4^{+}$fraction was isolated from these PBMC. The $\mathrm{CD}_{14}{ }^{+}$cells were cultured for 5 days in the presence of $800 \mathrm{U} / \mathrm{ml}$ human GM-CSF (Peprotech) and $500 \mathrm{U} / \mathrm{ml}$ human IL-4 (Peprotech). On day 5, the monocyte-derived DC (moDC; CD11 $\mathrm{c}^{+} \mathrm{CD} 1 \mathrm{a}^{+} \mathrm{CD} 14$ HLA-DR ${ }^{10}$ ) were stimulated with the indicated reagents for 48 hours. The concentration of IL-12p40 in the supernatant after 24 hours was measured by ELISA (BioLegend). After 48 hours, the moDC were stained with fluorescently labeled antibodies targeted to CD83, CD86 and HLA-DR (eBioscience), and analyzed by flow cytometry (BD).

WT and TLR2-expressing HEK293 cells (Invivogen) were cultured in IMDM supplemented with $100 \mathrm{IU} / \mathrm{ml}$ penicillin/streptomycin (Gibco), $2 \mathrm{mM}$
L-glutamin (Gibco) and 8\% fetal calf serum (FCS; PAA Laboratories). TLR2-HEK293 cells were cultured in the presence of $10 \mu \mathrm{g} / \mathrm{ml}$ of the selective antibiotic blasticidin. In a 96 wells plate, 20,000 HEK293 or TLR2-HEK293 cells were seeded per well and stimulated with titrating doses of the indicated compounds in duplicates. After 24 hours of incubation at $37^{\circ} \mathrm{C}$, supernatant was taken from all wells and the concentration of IL-8 was measured by ELISA (BioLegend).

\section{Detection of cytokine and chemokine concentrations}

The concentration of single cytokines was detected using standard sandwich ELISA assays (IL-8, IL$12 \mathrm{p} 40$, BioLegend; IFN $\gamma$, Sanquin), according to the manufacturer's instructions. To study the production of multiple cytokines and chemokines by moDCs or skinassociated cell populations in one sample, cell culture supernatants were subjected to Luminex analysis. For this purpose, a custom panel was set up consisting of reagents detecting the indicated cytokines and chemokines. A Bioplex suspension array system (Bio-Rad) was used to measure cytokine and chemokine concentrations. The analysis was performed according to the manufacturer's instructions (Bio-Rad). Data were analyzed using Bioplex Manager software.

\section{Activation of skin explant-derived cells}

Human skin explants were derived from patients undergoing plastic surgery after giving informed consent, as described earlier [29]. After intradermal injection of $10 \mu \mathrm{l}$ of the indicated reagents (4 nmole/injection), a biopsy with $6 \mathrm{~mm}$ diameter was taken of the injection site. The biopsies (10 for each reagent) were placed in a well to float freely with their epidermal side up on IMDM medium containing 10\% FCS. The biopsies were discarded after 48 hours and the pooled medium was analyzed for the presence of an array of chemokines and cytokines by Luminex technology (Bio-Rad) or ELISA (Sanquin). Flow cytometry was performed on a FACS Calibur (BD Biosciences) after staining migrated cells with fluorescent antibodies (BD Biosciences). An example of our gating strategy is presented in Supplementary Figure S4A.

\section{Proliferation of cancer patient derived $T$ cell clones}

The T cell clones C331.2, C331.11 and C427.215 specific for epitopes within HPV16 E6 $6_{71-95}$ and E6 $6_{127-158}$ as described in the results section were generated from PBMC of HPV16 ${ }^{+}$cervical cancer patients [30]. In a 96-well plate, HLA-matched DCs were loaded with the indicated reagents in titrated doses. After 24 hours, 
the DCs were washed and 50,000 T cells were added to each well. After 48 hours, supernatants were taken and subsequently the $\mathrm{T}$ cells were cultured in the presence of ${ }^{3} \mathrm{H}$ thymidine, which was incorporated in proliferating cells. The level of incorporated ${ }^{3} \mathrm{H}$-thymidine was measured as counts per minute (cpm) after 16 hours on a Liquid Scintillation counter (Wallac). The concentration of IFN $\gamma$ (in $\mathrm{pg} / \mathrm{ml}$ ) in the supernatants was determined by ELISA (Sanquin).

\section{Ex vivo stimulation of lymph node-derived $\mathrm{T}$ cells}

PBMC from patient C427 were seeded in 24-wells culture plates at a concentration of $2 \times 10^{6}$ cells $/ \mathrm{ml}$ and incubated for 2 hours in X-VIVO15 medium (Lonza), allowing monocytes to adhere to the bottom of the culture wells. After washing thoroughly to remove non-adherent cells, $1 \mu \mathrm{M}$ of the indicated reagents was loaded on the monocytes for 24 hours. The next day, the monocytes were washed again and then 500,000 LN-derived T cells (LN T cells) of patient C427 were added. During a 3-week culture period, fresh medium was added to the cultures or the cells were divided into new wells when necessary. Autologous monocytes were generated at the end of the culture period and loaded with either 22-mer SLPs [8] covering the amino acid sequences of the conjugated SLPs or with medium (nonstimulated control). The LN T cells were harvested and added to the peptide-loaded or non-loaded monocytes and incubated for 24 hours in the presence of $10 \mu \mathrm{g} /$ $\mathrm{ml}$ Brefeldin A (Sigma-Aldrich) and $10^{5} \mathrm{IU} / \mathrm{ml} \mathrm{IFN} \alpha$ (Roferon-A; Roche) [32]. The next day, the cells were harvested and stained with fluorescently labeled antibodies specific for CD3, CD4, CD8, CD137, CD154, IFN $\gamma$ and IL-2 in PBS containing $0.1 \%$ saponine, $0.5 \%$ BSA and $0.02 \%$ sodium azide. The expression of these markers was analyzed by flow cytometry (BD LSR2).

LN cells derived from an additional 6 cervical cancer patients who had been enrolled in the CIRCLE study (C822, C830, C879, C894, C896, C972) [30] were stimulated with a mix of both AV-SLP conjugates, a mix of both non-conjugated (free) SLPs or medium only. A culture period of 12 days was followed by overnight stimulation with 22-mer peptide loaded (or unloaded for unstimulated control cells) autologous monocytes as described above. For all cultures, a Th1/Th2 cytometric bead array (CBA; BD Biosciences) was performed on supernatant collected from LN cultures on day 7, except for the culture of C879 (collected on day 8). An intracellular cytokine staining was performed to analyze $\mathrm{T}$ cell responses after 12 days of culture. Responses with a stimulation index $>3$ over non-stimulated cells were considered positive.

\section{Statistical methods}

Statistical significance (Figure 4) was calculated using the Mann-Whitney U test. Statistical significance was defined as $\mathrm{p}<0.05$. In Table 2 , stimulation indices are shown, as calculated by division of the measured cytokine levels over non-stimulated control samples of the same patient. Positive responses defined as $\mathrm{SI}>3$, shown in bold; $<1$ indicates sample value was lower than medium control.

\section{ACKNOWLEDGMENTS}

We would like to thank Geert Haasnoot and Willem Verduijn for advice on the occurrence of HLA-alleles in the Netherlands and Els van Beelen for technical support in Luminex analysis.

\section{CONFLICTS OF INTEREST}

CJM Melief is chief scientific officer of biotech company ISA (Immune System Activation), aiming at development of synthetic peptide-based cancer vaccines, including conjugates between a proprietary TLR ligand and synthetic long peptides. As CSO, CJM Melief receives a salary from ISA and is in possession of stock appreciation rights. In addition CJM Melief is inventor on numerous patents that are licensed to or owned by ISA dealing with synthetic long peptide vaccines or dealing with the proprietary TLR ligand used in this paper.

\section{GRANT SUPPORT}

This work has been funded by a Dutch Cancer Society (KWF) grant (UL2007-3906).

\section{REFERENCES}

1. Rosalia RA, Quakkelaar ED, Redeker A, Khan S, Camps MGM, Drijfhout JW, Silva AL, Jiskoot W, Van Hall T, Van Veelen PA, Janssen G, Franken K, Cruz LJ, et al. Dendritic cells process synthetic long peptides better than whole protein, improving antigen presentation and T-cell activation. Eur. J. Immunol. 2013; 43: 2554-65.

2. Van der Burg SH, Arens R, Ossendorp F, Van Hall T, Melief CJM. Vaccines for established cancer: overcoming the challenges posed by immune evasion. Nat. Rev. Cancer 2016; 16: p219-233.

3. De Vos Van Steenwijk PJ, Heusinkveld M, Ramwadhdoebe TH, Löwik MJG, Van Der Hulst JM, Goedemans R, Piersma SJ, Kenter GG, Van Der Burg SH. An unexpectedly large polyclonal repertoire of HPV-Specific T cells is poised for action in patients with cervical cancer. Cancer Res. 2010; 70: 2707-2717. 
4. Welters MJP, Kenter GG, Piersma SJ, Vloon APG, Löwik MJG, Berends-van der Meer DMA, Drijfhout JW, Valentijn ARPM, Wafelman AR, Oostendorp J, Fleuren GJ, Offringa R, Melief CJM, et al. Induction of tumorspecific CD4+ and CD8+ T-cell immunity in cervical cancer patients by a human papillomavirus type 16 E6 and E7 long peptides vaccine. Clin. Canc. Res. 2008; 14: $178-87$.

5. Kenter GG, Welters MJP, Valentijn ARPM, Lowik MJG, Berends-van der Meer DMA, Vloon APG, Drijfhout JW, Wafelman AR, Oostendorp J, Fleuren GJ, Offringa R, Van der Burg SH, Melief CJM. Phase I immunotherapeutic trial with long peptides spanning the E6 and E7 sequences of high-risk human papillomavirus 16 in endstage cervical cancer patients shows low toxicity and robust immunogenicity. Clin. Cancer Res. 2008; 14: 169-77.

6. Kenter GG, Welters MJP, Valentijn ARPM, Lowik MJG, Berends-van der Meer DMA, Vloon APG, Essahsah F, Fathers LM, Offringa R, Drijfhout JW, Wafelman AR, Oostendorp J, Fleuren GJ, et al. Vaccination against HPV16 oncoproteins for vulvar intraepithelial neoplasia. New Engl J Med 2009; 361: 1838-47.

7. Van Poelgeest MI, Welters MJP, Vermeij R, Stynenbosch LF, Loof NM, Berends-van der Meer DMA, Lowik MJG, Hamming ILE, Van Esch EM, Hellebrekers BWJ, Van Beurden M, Schreuder HW, Kagie MJ, et al. Vaccination against oncoproteins of HPV16 for non-invasive vulvar/ vaginal lesions: lesion clearance is related to the strength of the T-cell response. Clin. Cancer Res. 2016; 22: 2343-50

8. Welters MJP, Kenter GG, De Vos van Steenwijk PJ, Löwik MJG, Berends-van der Meer DMA, Essahsah F, Stynenbosch LFM, Vloon APG, Ramwadhdoebe TH, Piersma SJ, Van der Hulst JM, Valentijn ARPM, Fathers LM, et al. Success or failure of vaccination for HPV16positive vulvar lesions correlates with kinetics and phenotype of induced T-cell responses. PNAS 2010; 107: 11895-99.

9. De Vos Van Steenwijk PJ, Van Poelgeest MIE, Ramwadhdoebe TH, Löwik MJG, Berends-Van Der Meer DMA, Van Der Minne CE, Loof NM, Stynenbosch LFM, Fathers LM, Valentijn ARPM, Oostendorp J, Osse EM, Fleuren GJ, et al. The long-term immune response after HPV16 peptide vaccination in women with low-grade pre-malignant disorders of the uterine cervix: A placebocontrolled phase II study. Cancer Immunol. Immunother. 2014; 63: 147-160.

10. Baumgartner P, Nunes C, Cachot A, Hajjami H, Cagnon L, Braun M, Derré L, Rivals JP, Rimoldi D, Romano E, Michielin O, Romero P, Jandus C, Speiser DE. Vaccination with long NY-ESO-1 79-108 peptide and CpG-B leads to robust activation of CD4 and CD8 $\mathrm{T}$ cell responses in stage
III/IV melanoma patients, and a new HLA-DR7 epitope. J. Immunother. Cancer 2015; 3: 437.

11. Park H, Adamson L, Ha T, Mullen K, Hagen SI, Nogueron A, Sylwester AW, Axthelm MK, Legasse A, Piatak M, Lifson JD, McElrath JM, Picker LJ, Seder RA. Polyinosinic-polycytidylic acid is the most effective TLR adjuvant for SIV Gag protein-induced $\mathrm{T}$ cell responses in nonhuman primates. J. Immunol. 2013; 190: 4103-15.

12. Duthie MS, Windish HP, Fox CB, Reed SG. Use of defined TLR ligands as adjuvants within human vaccines. Immunol. Rev. 2011; 239: 178-196

13. Welters MJP, Bijker MS, Van den Eeden SJF, Franken KLMC, Melief CJM, Offringa R, Van der Burg SH. Multiple CD4 and CD8 T-cell activation parameters predict vaccine efficacy in vivo mediated by individual DC-activating agonists. Vaccine 2007; 25: 1379-1389.

14. Khan S, Bijker MS, Weterings JJ, Tanke HJ, Adema GJ, Van Hall T, Drijfhout JW, Melief CJM, Overkleeft HS, Van Der Marel GA, Filippov DV, Van Der Burg SH, Ossendorp F. Distinct uptake mechanisms but similar intracellular processing of two different toll-like receptor ligand-peptide conjugates in dendritic cells. J. Biol. Chem. 2007; 282: 21145-21159.

15. Zom GG, Khan S, Britten CM, Sommandas V, Camps MGM, Loof NM, Budden CF, Meeuwenoord NJ, Filippov DV, Van der Marel GA, Overkleeft HS, Melief CJM, Ossendorp F. Efficient Induction of Antitumor Immunity by Synthetic Toll-like Receptor Ligand-Peptide Conjugates. Cancer Immunol. Res. 2014; 2: 756-764.

16. Zom GG, Khan S, Filippov DV, Ossendorp F. TLR LigandPeptide Conjugate Vaccines. Toward Clinical Application. Adv. Immunol. 2012; 114: 177-201.

17. Zom GG, Filippov DV, Van der Marel GA, Overkleeft HS, Melief CJM, Ossendorp F. Two in one: improving synthetic long peptide vaccines by combining antigen and adjuvant in one molecule. Oncoimmunology 2014; 3: e947892.

18. Khan S, Weterings JJ, Britten CM, De Jong AR, Graafland D, Melief CJM, Van der Burg SH, Van der Marel GA, Overkleeft HS, Filippov DV, Ossendorp F. Chirality of TLR-2 ligand Pam3CysSK4 in fully synthetic peptide conjugates critically influences the induction of specific CD8+ T-cells. Mol. Immunol. 2009; 46: 1084-1091.

19. De Vos Van Steenwijk PJ, Ramwadhdoebe TH, Löwik MJG, Van Der Minne CE, Berends-Van Der Meer DMA, Fathers LM, Valentijn ARPM, Oostendorp J, Fleuren GJ, Hellebrekers BWJ, Welters MJP, Van Poelgeest MI, Melief CJM, et al. A placebo-controlled randomized HPV16 synthetic long-peptide vaccination study in 
women with high-grade cervical squamous intraepithelial lesions. Cancer Immunol. Immunother. 2012; 61: 1485-1492.

20. Van den Hende M, Van Poelgeest MIE, Van der Hulst JM, De Jong J, Drijfhout JW, Fleuren GJ, Valentijn ARPM, Wafelman AR, Slappendel GM, Melief CJM, Offringa R, Van der Burg SH, Kenter GG. Skin reactions to human papillomavirus (HPV) 16 specific antigens intradermally injected in healthy subjects and patients with cervical neoplasia. Int. J. Cancer 2008; 123: 146-52.

21. Oosterhoff D, Heusinkveld M, Lougheed SM, Kosten I, Lindstedt M, Bruijns SCM, Van Es T, Van Kooyk Y, Van der Burg SH, De Gruijl TD. Intradermal delivery of TLR agonists in a human explant skin model: preferential activation of migratory dendritic cells by polyribosinicpolyribocytidylic acid and peptidoglycans. J. Immunol. 2013; 190: 3338-45.

22. Welters MJP, De Jong A, Van den Eeden SJF, Van der Hulst JM, Kwappenberg KMC, Hassane S, Franken KLMC, Drijfhout JW, Fleuren GJ, Kenter GG, Melief CJM, Offringa R, Van der Burg SH. Frequent display of human papillomavirus type 16 E6-specific memory T-helper cells in the healthy population as witness of previous viral encounter. Cancer Res. 2003; 63: 636-641.

23. De Jong A, Van der Hulst JM, Kenter GG, Drijfhout JW, Franken KLMC, Vermeij P, Offringa R, Van der Burg SH, Melief CJM. Rapid enrichment of human papillomavirus (HPV)-specific polyclonal T cell populations for adoptive immunotherapy of cervical cancer. Int. J. Cancer 2005; 114: 274-82.

24. Willems MMJHP, Zom GG, Khan S, Meeuwenoord NJ, Melief CJM, Van der Stelt M, Overkleeft HS, Codée JDC, Van der Marel GA, Ossendorp F, Filippov DV. N-tetradecylcarbamyl lipopeptides as novel agonists for Toll-like receptor 2. J. Med. Chem. 2014; 57: 6873-8.

25. Ben-Ali M, Corre B, Manry J, Barreiro LB, Quach H, Boniotto M, Pellegrini S, Quintana-Murci L. Functional characterization of naturally occurring genetic variants in the human TLR1-2-6 gene family. Hum. Mutat. 2011; 32: 643-652.

26. Zhang Y, Jiang T, Yang X, Xue Y, Wang C, Liu J, Zhang $\mathrm{X}$, Chen Z, Zhao M, Li JC. Toll-like receptor -1 , -2 , and -6 polymorphisms and pulmonary tuberculosis susceptibility: a systematic review and meta-analysis. PLoS One 2013; 8: e63357.

27. Van Bergenhenegouwen J, Plantinga TS, Joosten LAB, Netea MG, Folkerts G, Kraneveld AD, Garssen J, Vos AP. TLR2 \& Co: a critical analysis of the complex interactions between TLR2 and coreceptors. J. Leukoc. Biol. 2013; 94: 885-902.

28. Varypataki EM, Van der Maaden K, Bouwstra J, Ossendorp F, Jiskoot W. Cationic liposomes loaded with a synthetic long peptide and poly(I:C): a defined adjuvanted vaccine for induction of antigen-specific T cell cytotoxicity. AAPS J 2015; 17: 216-26.

29. De Gruijl TD, Luykx-de Bakker SA, Tillman BW, Van den Eertwegh AJM, Buter J, S. Lougheed SM, van der Bij GJ, Safer AM, Haisma HJ, Curiel DT, Scheper RJ, Pinedo HM, Gerritsen WR. Prolonged maturation and enhanced transduction of dendritic cells migrated from human skin explants after in situ delivery of CD40targeted adenoviral vectors. J. Immunol. 2002; 169: 5322-5331.

30. Piersma SJ, Welters MJP, Van Der Hulst JM, Kloth JN, Kwappenberg KMC, Trimbos BJ, Melief CJM, Hellebrekers BW, Fleuren GJ, Kenter GG, Offringa R, Van Der Burg SH. Human papilloma virus specific $\mathrm{T}$ cells infiltrating cervical cancer and draining lymph nodes show remarkably frequent use of HLA-DQ and -DP as a restriction element. Int. J. Cancer 2008; 122: 486-494.

31. Van der Burg SH, Ressing ME, Kwappenberg KMC, De Jong A, Straathof K, De Jong J, Geluk A, Van Meijgaarden KE, Franken KLMC, Ottenhoff TH, Fleuren GJ, Kenter GG, Melief CJM, Offringa R. Natural T-helper immunity against human papillomavirus type 16 (HPV16) E7-derived peptide epitopes in patients with HPV16-positive cervical lesions: identification of 3 human leukocyte antigen class II-restricted epitopes. Int. J. Cancer 2001; 91: 612-8.

32. Singh SK, Tummers B, Schumacher TN, Gomez R, Franken KLMC, Verdegaal EM, Laske K, Gouttefangeas C, Ottensmeier C, Welters MJP, Britten CM, Van der Burg SH. The development of standard samples with a defined number of antigen-specific $\mathrm{T}$ cells to harmonize $\mathrm{T}$ cell assays: a proof-of-principle study. Cancer Immunol. Immunother. 2013; 62: 489-501.

33. Andres PG, Beck PL, Mizoguchi E, Mizoguchi A, Bhan AK, Dawson T, Kuziel WA, Maeda N, MacDermott RP, Podolsky DK, Reinecker HC. Mice with a selective deletion of the $\mathrm{CC}$ chemokine receptors 5 or 2 are protected from dextran sodium sulfate-mediated colitis: lack of $\mathrm{CC}$ chemokine receptor 5 expression results in a NK1.1+ lymphocyte-associated Th2-type immune response in the intestine. J. Immunol. 2000; 164: 6303-12.

34. Maurer M, Von Stebut E. Macrophage inflammatory protein-1. Int. J. Biochem. Cell Biol. 2004; 36: 1882-6.

35. Groux H, Bigler M, De Vries JE, Roncarolo MG. Inhibitory and stimulatory effects of IL-10 on human CD8+ T cells. J. Immunol. 1998; 160: 3188-93.

36. Santin AD, Hermonat PL, Ravaggi A, Bellone A, Pecorelli S, Roman JJ, Parham GP, Cannon MJ. Interleukin-10 increases Th1 cytokine production and cytotoxic potential in human papillomavirus-specific $\mathrm{CD} 8(+)$ cytotoxic $\mathrm{T}$ lymphocytes. J Virol 2000; 74: 4729-4737. 
37. Van Montfoort N, Camps MGM, Khan S, Filippov DV, Weterings JJ, Griffith JM, Geuze HJ, Van Hall T, Verbeek JS, Melief CJM, Ossendorp F. Antigen storage compartments in mature dendritic cells facilitate prolonged cytotoxic T lymphocyte cross-priming capacity. Proc. Natl. Acad. Sci. U. S. A. 2009; 106: 6730-5.

38. Van Poelgeest MIE, Welters MJP, Van Esch EM, Stynenbosch LFM, Kerpershoek G, Van Persijn van
Meerten EL, Van den Hende M, Löwik MJG, Berends-van der Meer DMA, Fathers LM, Valentijn ARPM, Oostendorp J, Fleuren GJ, et al. HPV16 synthetic long peptide (HPV16SLP) vaccination therapy of patients with advanced or recurrent HPV16-induced gynecological carcinoma, a phase II trial. J. Transl. Med. 2013; 11. 